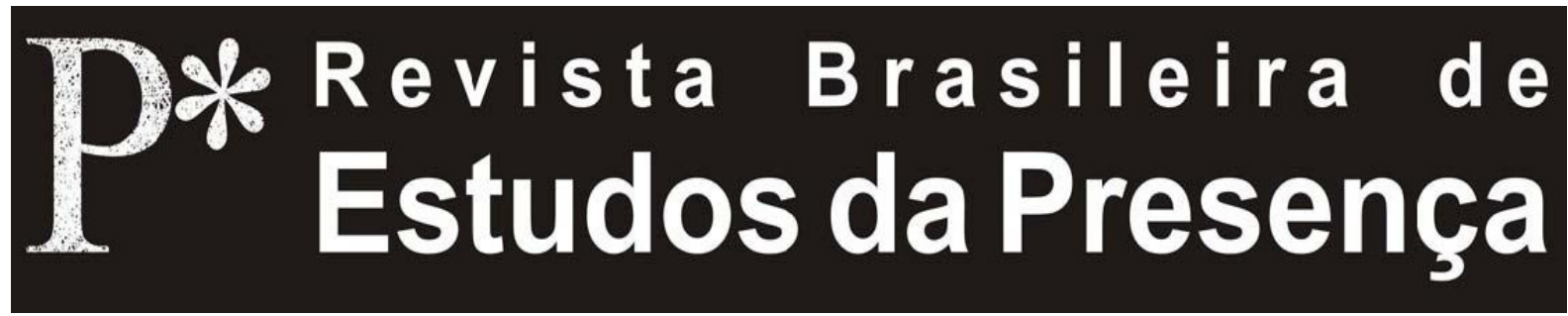

DOI - http://dx.doi.org/10.1590/2237-266025484

ISSN 2237-2660

\title{
Traducir la Muerte para Pensar el Arte: apuntes sobre la escenta posdramática
}

Beatriz Trastoy

Universidad de Buenos Aires - UBA, Buenos Aires, Argentina

RESUMEN - Traducir la Muerte para Pensar el Arte: apuntes sobre la escena posdramática - La (imposible) presentación escénica de la muerte plantea nuevos desafíos para las prácticas y para la teoría de las artes escénicas contemporáneas, sobre los que aquí intentaremos reflexionar. Para ello, consideraremos algunos ejemplos del teatro argentino de los últimos años: Los muertos (Ensayo sobre representaciones de la muerte en la Argentina), estrenada en 2005, escrita y dirigida por Beatriz Catani y Mariano Pensotti, y Adonde van los muertos (Lado B), 2010, y su precuela, Adonde van los muertos (Lado A), 2011, creación del Grupo Krapp. Palabras-clave: Teatro. Teatro Posdramático. Artes Escénicas. Muerte. Crítica.

ABSTRACT - Translating Death to Think About Art: notes on the postdramatic scene - This article focuses on the (impossible) scenic presentation of death, raising new practical and theoretical challenges for contemporary performing arts. With this aim, we will consider some examples of the Argentine theatre in recent years: Los muertos (Ensayo sobre representaciones de la muerte en la Argentina), 2005, written and staged by Beatriz Catani and Mariano Pensotti, and Adonde van los muertos (Lado B), 2010, along with its prequel, Adonde van los muertos (Lado A), 2011, a creation by the Krapp group.

Keywords: Theatre. Postdramatic Theatre. Performing Arts. Death. Critique.

RÉSUMÉ - Traduire la Mort pour Réfléchir sur l'Art: notes sur la scène postdramatique - L'auteur se propose d'examiner la (impossible) présentation scénique de la mort, qui pose des nouveaux défis pour les pratiques et pour la théorie des arts scéniques contemporains. Pour ce faire, il examine quelques exemples du théâtre argentin des dernières années: Los muertos (Ensayo sobre representaciones de la muerte en la Argentina, 2005), écrit et mis en scène par Beatriz Catani et Mariano Pensotti, et Adonde van los muertos (Lado B) (2010) et sa préquelle, Adonde van los muertos (Lado A) (2011), création du groupe Krapp.

Mots-clés: Théâtre. Théâtre Postdramatique. Arts du Spectacle. Mort. Critique. 
1. La teoría teatral del siglo XX, fuertemente atravesada por lineamientos formalistas, tendió a relegar la reflexión sobre cuestiones de índole temática. Por cierto, del mismo modo en que las casi trescientas figuras retóricas, más allá de los diferentes criterios taxonómicos que buscan agruparlas, pueden reducirse a dos, metáfora y metonimia, el teatro occidental, desde sus orígenes mismos, transita de múltiples formas los vastos campos semánticos desplegados también por dos tópicos esenciales: la vida y la muerte. Así, el complejo entramado de pulsiones relacionadas con lo vital - amores, pasiones, odios, celos, venganzas, fe, ambiciones, engaños, equívocos, traiciones, anhelos, desesperanzas - se entrecruzan con la muerte (y sus múltiples configuraciones), transformada en causa motivadora o en temida - o inclusive deseada - consecuencia de las acciones humanas.

Sin embargo, el interés teórico por las postergadas cuestiones temáticas parece revitalizarse en el marco de las postulaciones escénicas contemporáneas posrepresentacionales, posantropocéntricas, posorgánicas o, más generalizadamente, siguiendo a Lehmann (2002) posdramáticas. En ellas, la vida y la muerte - y el cúmulo de sus derivaciones semánticas no dejan de ser temas insoslayables (¿de qué otra cosa podría hablar el arte?), pero ya no urden, como en el teatro tradicional, los conflictos, los enfrentamientos, las reconciliaciones entre los personajes, porque, entre otras cosas, éstos han dejado de existir como tales. En efecto, esta nueva modalidad escénica pone en crisis la noción aristotélica de representación como instancia fundacional del teatro, es decir, como reproducción de personas y acciones, remitiendo a otra cosa diferente de sí. Ya no busca ser espejo escénico, duplicación de similares experiencias existenciales que, por su atribuida validez universal, aseguran los procesos de identificación emocional del espectador. Por el contrario, se centra en la noción de presentación, es decir, acentúa el aspecto productivo, en tanto privilegia el cuerpo del artista, cuyo trabajo se desenvuelve en espacio y en tiempo reales. A través de la autorreflexión plasmada en procedimientos que conciernen no sólo a las diferentes instancias de la producción, sino también de la cir- 
culación y de los mecanismos de su recepción, las prácticas escénicas contemporáneas diluyen y flexibilizan los límites entre los géneros, al tiempo que relativizan los criterios que permitían diferenciar las nociones de veracidad y verosimilitud, de ficción escénica y realidad.

En este desplazamiento de la representación hacia la presentación, característico del teatro posdramático, la vida suele asumir visajes vinculados a la narración (auto)biográfica del artista, convertido así en sujeto/objeto (ya no en personaje). Los realizadores responsables de los espectáculos posdramáticos - cada uno a su manera, con disímiles perspectivas ideológicas y planteando modalidades teatrales también diferentes - actualizan en escena el relato autobiográfico para preguntarse si en estas sociedades modernizadas por las nuevas tecnologías es posible contar la vida en escena, representar lo irrepresentable, hacer real la ficción y, al mismo tiempo, ficcionalizar lo real, solamente (o, quizás, fundamentalmente) por medio de palabras, haciendo que los objetos - lo que ellos puedan decir, lo que ellos puedan contar - cobren, asimismo, una relevancia inusitada. En estos nuevos escenarios de lo real autobiográfico, se busca experimentar, por un lado, con la reconfiguración de la noción de una intimidad donde ya no impera ni el secreto ni el pudor que parecía definirla, ni, menos aún, la idea de la contemplación introspectiva, entendida como un necesario camino de conocimiento de sí. Por otro lado, se experimenta con la posibilidad de poner en escena lo más propio, lo más personal, impugnando, simultáneamente, las prácticas de la vida pública, la acción política y sus discursos, percibidos como falaces y manipuladores (Sibila, 2008).

En la escena contemporánea, esta tendencia a la presentación hiperrealista de la vida tiene, sin embargo, un único e infranqueable límite: la muerte. Su problematización posdramática, fechable grosso modo en la década del 60 , ya se evidencia en el marco precursor de las llamadas vanguardias históricas. Al respecto, José Antonio Sánchez (2007) observa que, a comienzos del siglo XX, el énfasis puesto por el surrealismo y el expresionismo en la indisociabilidad de lo psíquico y lo corporal determinó que quien pretendiera abordar lo irre- 
presentable, es decir, el preciso momento de la muerte, ya no podría limitarse a plasmar aisladamente ni las transformaciones materiales orgánicas ni los procesos psicológicos, sino, por el contrario, debía concebir de modo integral la aproximación del sujeto hacia el otro lado o hacia el exterior de la realidad, en términos simbolistas y materialistas.

¿Es posible, entonces, trascender lo representacional y presentar la muerte en escena? Matar o morir por propia decisión o, inclusive, hacerlo sobre un escenario tras una exhibida agonía, excedería lo puramente artístico para devenir, seguramente, un hecho moralmente cuestionable o directamente delictivo de alcances punibles, tal como sucede con las películas snuff, en las se filman asesinatos reales con fines de distribución comercial. La muerte como límite de lo real en el teatro posdramático plantea, por lo tanto, nuevos desafíos para las prácticas y para la teoría de las artes escénicas sobre los que aquí intentaremos reflexionar. Para ello, consideraremos algunos ejemplos del teatro argentino de los últimos años: la puesta en escena de Los muertos (Ensayo sobre representaciones de la muerte en la Argentina), estrenada en 2005 en el Hebbel am Ufer de Berlín, y luego presentada en Buenos Aires en 2006 y 2007, escrita y dirigida por Beatriz Catani y Mariano Pensotti y Adonde van los muertos (Lado B) (2010) y su precuela, Adonde van los muertos (Lado A), estrenada al año siguiente, creación del Grupo Krappque integrado por Gabriel Almendros, Edgardo Castro, Fernando Tur, Luciana Acuña, Luis Biasotto; éstos dos últimos a cargo también de la dirección de ambos espectáculos.

Si bien se insertan en la problemática de la presentación de lo real, los tres espectáculos seleccionados se alejan por completo tanto de lo macabro, lo abyecto, lo siniestro y lo monstruoso, categorías propias de las poéticas de lo cadavérico a lo largo de la historia artística de Occidente, estudiadas recientemente por Adriana Musitano (2011) en una investigación sobre las producciones del teatro, la plástica y el videoarte argentinos de fines del siglo XX, así como también se alejan de la intencionalidad política de perspectiva coyuntural que, según la autora, caracterizó dichas prácticas artísticas. En 
efecto, consideramos que el interés de estos tres espectáculos seleccionados a modo de ejemplo radica precisamente en superar lo transitivo para explorar el tema de la muerte desde una perspectiva netamente reflexiva.

2. La puesta en escena de Los muertos (Ensayo sobre representaciones de la muerte en la Argentina) se estructura, básicamente, en torno de dos monólogos desarrollados a partir de secuencias alternadas en áreas escénicas diferentes, que no interfieren entre sí: por un lado, el del actor Alfredo Martín quien, dirigiéndose al público, se presenta con su verdadero nombre y cuenta un grave accidente automovilístico que sufriera su hermano. Luego, explica al público que narró este evento familiar porque los directores, cuyos nombres reales no se mencionan en ningún momento del espectáculo, le pidieron que hablara de una experiencia reciente con la muerte. De inmediato, comenta que intentará reconstruir - también por pedido de los directores - la puesta en escena de $L O S$ muertos, adaptada del cuento homónimo de James Joyce, supuesto espectáculo del que participara en un rol ínfimo varias décadas atrás, en la provincia de Corrientes, de donde dice ser oriundo. Alfredo Martín narra - esto es, presenta - una puesta en escena y, sólo eventualmente, representa a algunos de los principales personajes de la obra en cuestión, planteando así la oposición básica entre los modos escénicos de presentación y de representación. No sólo pone el acento en el hecho mismo de su condición de actor de un espectáculo teatral a quien se le ha encomendado la labor escénica de narrar y no representar otro espectáculo teatral, sino también en el modo en que construyó el relato de la re-construcción de una puesta en escena, proceso que lo llevó a transitar - y a poner en escena, es decir, a representarlos - casi todos los roles artísticos y no artísticos vinculados al hecho teatral: investigador, historiador, autor, director, intérprete, crítico.

Por otro lado, en el sector opuesto del escenario, a partir de las imágenes que se visualizan en un televisor (monumentos fúnebres de cementerios de Buenos Aires, artistas argentinos representando escenas cinematográficas de muerte, entrevistas a sepultureros y a técnicos teatrales), el actor Matías Vértiz 
también monologa reflexionando acerca de las múltiples analogías que vinculan teatro y cementerio: la teatralidad que ambos generan, la concepción y el funcionamiento de los cuerpos en cada uno de ellos, las equivalencias estéticas entre escenografía escénica y arquitectura funeraria, las fuentes teóricas utilizadas como punto de partida de dicha reflexión (un texto de Habermas) y la cantidad y causa de muertes reales ocurridas durante la preparación del espectáculo. La primera y la última de las nueve secuencias que componen el monólogo de Matías Vértiz también contienen referencias al contexto social en el que se insertaron las condiciones de producción del espectáculo; esto es, se alude a algunos informes estadísticos surgidos a partir de la investigación en instituciones públicas, hospitales y cárceles; se enuncian datos acerca de la cantidad y causa de las muertes producidas en el país durante la elaboración de la obra, provocadas por accidentes laborales, de tránsito o catástrofes naturales; el número y el análisis porcentual de las edades de las víctimas del denominado gatillo fácil de la policía; las personalidades del mundo del espectáculo nacional fallecidas en ese período. Asimismo, comenta datos referidos a los conflictos que se dan en ciertas comunidades por posesión de tierra en cementerios, a la cada vez más habitual práctica de venta telefónica de parcelas familiares en necrópolis privadas, a los numerosos cementerios virtuales interactivos para humanos y mascotas que, desde el comienzo del nuevo siglo, ofrece la Internet. Hace referencia también a las nuevas propuestas empresariales orientadas a resolver el destino final de los restos de los restos, tales como la solemne dispersión de las cenizas realizada desde un barco, la posibilidad de hacerlas girar eternamente alrededor de la Tierra en un nave espacial, especialmente diseñada para tal efecto o, inclusive, la posibilidad de depositar algunos gramos de ellas en la Luna, creando así una especie de camposanto selenita, que, en un futuro no muy lejano, podría ser visitado regularmente por los deudos. Las otras secuencias del texto enunciado por Vértiz se construyen a modo de quasi-monólogo o quasi-diálogo con las imágenes de video que se ven en el televisor - sobre las que no se puede afirmar con precisión 
si ilustran el discurso verbal del actor o si son ilustradas por él - y con el traductor, Nikolaus Kirstein, de quien no espera una réplica a sus palabras, sino la versión al alemán de lo que enuncia. El actor reflexiona en torno de los distintos lenguajes expresivos que establecen paralelismos entre cementerios y teatro, a partir de preguntas implícitas acerca de qué se ve y qué vemos en la escenografía/arquitectura de cada uno de ellos, en tanto puestas en escena de que hacen presentes los cuerpos ausentes. En las imágenes del video que reproduce el televisor se observan los monumentos funerarios que prolongan más allá de la vida las diferencias sociales entre ricos y pobres, como así también las tumbas de los artistas, cuyas imágenes retoman momentos de esplendor en el ejercicio de su arte. Se repiensa el gusto de los actores por representar escenas de muerte y se detiene en el cine argentino, más precisamente en una escena del film La Mary (1974), dirigida por Daniel Tinayre, donde la protagonista (Susana Giménez) asesina a su marido, interpretado por Carlos Monzón, ex campeón mundial de boxeo en la vida real quien, años más tarde, asesinaría a golpes a su esposa. Vértiz incorpora en su monólogo las reflexiones de especialistas - un sepulturero y un técnico teatral - que se reproducen en el video, sobre las tareas de los trabajadores de cementerios que, al inhumarlos, ocultan los cuerpos y las de sus equivalentes, los técnicos teatrales (iluminadores, sonidistas, etc.), que hacen ver y oír a los cuerpos en escena, aunque su propia presencia no sea visible o no sea visualizada por los asistentes a las respectivas ceremonias. En las entrevistas, ambos explican cuándo usan guantes (por higiene y por seguridad, respectivamente), cómo llegaron a desempeñar esas funciones, cómo se relacionan con el público de cada lugar, cómo se emocionan frente al dolor de la pérdida y frente a un estreno. Vértiz explicita que cierto texto de Habermas ha sido el marco teórico de su propio discurso, y, en última instancia, del proyecto escénico de Catani-Pensotti, y lo desplaza al plano social local, al presentar la Argentina como un país de muertes en tierras lejanas y de cuerpos ausentes (Mariano Moreno, Jorge Luis Borges, Eva Perón, Carlos Gardel, los desaparecidos durante la última dictadura militar). 
El gesto autobiográfico/autoficcional del relato de Alfredo Martín y la documentada - digamos - veracidad de los comentarios de Matías Vértiz resignifican las consideraciones sobre los modos de enunciación - presentación/representación, realidad/ficción - presentes en ambos monólogos, en tanto se articulan con las complejas mediaciones que atañen al nivel del enunciado. En efecto, son ampliamente conocidas las marcas autobiográficas joyceanas presentes en "Los muertos": al igual que Gretta Conroy, Nora Barnacle, la esposa de Joyce, era oriunda de Galway; como Gretta, Nora había sido amada por un joven que murió por ella; como Gabriel Conroy, Joyce sentía celos por ese amor de juventud de Nora; como Gabriel y Miss Ivors, los desacuerdos ideológicos con el nacionalismo irlandés frustraron una supuesta relación afectiva entre el escritor y una militante; como Gabriel, Joyce escribía en inglés y no en gaélico, lengua que consideraba artificialmente reivindicada. En la obra de Cattani-Pensotti ${ }^{1}$ también se hace fuerte referencia al carácter autobiográfico de la producción artística la transposición fílmica del cuento de Joyce, The dead (1987), dirigida por John Huston, a la que sin nombrarla se alude sutilmente a través del reemplazo del recitado de " $D o$ nalÓg" - secuencia inexistente en el texto original de Joyce - por "De súbito, estalló la guerra" de la poeta, actriz y performer uruguaya Marosa Di Giorgio, cuya peculiar dicción es parodiada por Alfredo Martín en su declamación. Asimismo, se apela implícitamente a la enciclopedia del espectador: es bien sabido que semanas antes de morir, John Huston dirigió The dead desde su silla ruedas con asistencia respiratoria; la película fue protagonizada por su hija Anjelica, mientras que Tony, también hijo del director, fue el guionista. Precisamente, el desolado llanto de Gretta, en la decisiva escena final, es difícilmente separable del de la actriz-hija, a quien no podemos dejar de imaginar profundamente atravesada por el dolor de estar no sólo participando de la última película de su padre, sino asistiendo a los últimos momentos de su vida ${ }^{2}$.

De un lado del escenario, entonces, Alfredo Martín y el teatro, la representación y la narración escénica, la remake, es decir, la ficción y sus problemáticas; del otro lado, Matías 
Vértiz y los testimonios y documentos, los lenguajes visuales que los conservan y diseminan (el video, el cine, lo televisivo), es decir, la realidad y sus problemáticas: mediando entre ambos intérpretes - y también entre escenario y platea - el traductor. Con tono neutro, opinando a veces, seleccionando, sintetizando, agregando datos, mostrando sus dificultades en encontrar las equivalencias lingüísticas, el traductor vuelca al alemán todos los comentarios de Vértiz y sólo algunos de los que corresponden a la reconstrucción escénica a cargo de Alfredo Martín. Entre ambos monólogos y, a su vez, entre escenario y platea, se despliega un complejo juego de múltiples mediaciones que conciernen tanto al nivel de la enunciación como al del enunciado, indisolublemente vinculadas entre sí.

La presencia escénica del traductor resulta en el espectáculo de Catani-Pensotti lingüísticamente tan innecesaria en Buenos Aires, como en ocasión de su estreno en Berlín, ya que las opciones para acercar un texto a quienes no conocen la lengua en la que éste se enuncia pueden ser otras, como el subtitulado, la entrega del texto parcial o completo a los espectadores, la síntesis argumental en el programa de mano etc. La traducción al alemán realizada en el escenario fue seriamente objetada, especialmente por los realizadores locales, ya que se la consideró una concesión estética exclusivamente destinada a lograr su presentación en ámbitos internacionales. Desde mi punto de vista, por el contrario, la presencia escénica del intérprete (intérprete en su doble acepción de traductor y actor), como así también la modalidad de su interacción con los otros dos actores/intérpretes, encubre y, al mismo tiempo, condensa y devela la traducción (entendida en sentido amplio como traslación, adaptación, paráfrasis, comentario, parodia, reescritura, transformación, apropiación, cita, mediación) como una de las posibles interpretaciones del espectáculo.

3. En Adonde van los muertos (Lado B) (2010) del grupo Krapp, un extenso video proyectado en tamaño natural en el que varias personas de diferentes edades, recortándose sobre un inquietante fondo blanquísimo e inerte, comentan sus fantasías y sus temores en torno de la idea de muerte, de su propia muerte y de la de quienes los rodean, sirve como 
punto de partida para una suerte de ensayo, de preparación, de reflexión escénica acerca de una futura obra que se estrenó al año siguiente con el título de Adonde van los muertos (Lado $A$ ). En el video, los entrevistados parecen responder a una serie de preguntas (“ $¿ E s$ cierto que lo primero que se olvida de alguien que muere, es el sonido de su voz? ¿A quién vería por última vez? ¿Qué prefiere: bailar la muerte o matar la danza? ¿Es la muerte parte de un plan? ¿Dormir es parecido a morir?") que, explícita o implícitamente, atraviesan la totalidad del espectáculo y organizan su sentido último. Al respecto, el videasta invitado, Alejo Moguillansky (Lingenti, 2011), a cargo del montaje fílmico, recuerda que la profunda tristeza que se desprende del mismo no tiene que ver con lo que los entrevistados responden, con lo sorprendente de sus cuestionamientos, con su ocasional sentido del humor, sino la cadencia de cada uno, sus silencios, sus pausas, la dolorosa conciencia de lo inevitable que se deja adivinar tras sus palabras.

Los intérpretes e, inclusive, sus colaboradores técnicos - iluminadores, sonidistas - intentan hablar escénicamente sobre la muerte para hablar de otra obra (el futuro Lado A) o viceversa. Por medio de diferentes lenguajes pretenden metaforizar lo irrepresentable, decir escénicamente lo indecible en tiempos en los que la lengua ha dejado de ser garantía de sentido. Así, muestran la vida que pretende negar lo humano - y por ende, su finitud - mecanizándose en un robot; un picadito de fútbol que reproduce la energía y el compromiso del deporte aún cuando no haya espacio físico para desarrollarse ni objetivo a alcanzar; un cronómetro que nos recuerda que la cuenta regresiva no sólo se usa para ritualizar los momentos de cambio, los despegues hacia el cielo, el final de un año, sino también nuestro inexorable límite existencial; un caballo formado por dos de los integrantes que, montado por Luciana Acuña, vaga tristemente buscando un rumbo inhallable. Cada prueba realizada en escena es luego evaluada por la totalidad de los integrantes del grupo a través de la repetición alternada de frases idénticas, que pueden interpretarse ya sea como parodia a los supuestos lugares comunes atribuibles al espectador común o inclusive a la crítica teatral especializada, 
o bien - lo que resulta más interesante y original - como un modo de mostrar que entre escenario y platea las dudas, las incertidumbres, los puntos de vista sobre la muerte y sobre el teatro no difieren en lo esencial. Esta última perspectiva parece reforzarse con la elección al azar de un espectador a quien, por medio de auriculares, se le dicta un texto referido a la temática que organiza la puesta en escena, pero también a su propio lugar en ella, a su específica condición de espectador, texto que debe repetir en voz alta, frente a un micrófono, para el resto del público, al comienzo y al final del espectáculo.

En Adonde van los muertos (Lado A), las opiniones de entrevistados desconocidos son reemplazadas por la consulta, también en video y presentada en tamaño natural, a diez artistas contemporáneos y vinculados de algún modo a la actividad escénica del país. Fabiana Cariotti, Rafael Spregelburd, Diana Szeinblum, Federico León, el suizo Stefan Kaegi, Mariano Pensotti, el francés François Chaignaud, Lola Arias, Mariano Llinás y Fabián Gandini, todos ellos coreógrafos, dramaturgos, directores teatrales y de cine, ofrecen diferentes respuestas a la pregunta “¿Cómo representaría usted la muerte en escena?”. De inmediato, los integrantes de Krapp intentan llevarlas a escena. Recurriendo fundamentalmente al lenguaje de la corporalidad, se busca plasmar la idea del tiempo del muerto $\mathrm{y}$ de la muerte por medio de una marcha de ida y vuelta entre dos puntos fijos, a la que se van sumando de a uno todos los intérpretes, cuya abrumadora y triste monotonía termina anulando la temporalidad; la idea del cuerpo que desaparece bajo la ropa, intentando captar el instante del tránsito a través del momento en que Don Quijote deja su ropaje de personaje para ser nuevamente - o quizás para recién entonces ser por fin y definitivamente - Alfonso Quijano; la idea de la lucha entre vida y muerte, entre salud y enfermedad; la de muerte como final escénico de una obra que no vemos pero tal vez adivinamos, o la idea de imposible realización de presentar cuerpos ausentes propuesta por Mariano Pensotti, precisamente, uno de los directores de Los muertos (Ensayo sobre representaciones de la muerte en la Argentina). La intervención de Lola Arias da un giro particular a esta reflexión sobre la posibilidad de 
representar/la imposibilidad de presentar la muerte en escena. En efecto, la dramaturga y directora teatral, eludiendo la esperada respuesta, reprocha a los miembros de Krapp por no haber hecho explícito en el espectáculo anterior - (Lado $B)$ - lo que motivó la idea original de ambos espectáculos, lo que verdaderamente les duele: no la muerte en general, en abstracto, sino la muerte concreta, la de Marcelo Álvarez, iluminador del grupo. A partir de la revelación de ese dato escamoteado, no sólo se desplaza el predominio del lenguaje corporal hacia el de las luces (focos devenidos ojos sin cuerpo, ojos que parpadean y que finalmente se apagan), sino también el juego de sus posibles interpretaciones.

4. En la escena posdramática, la vida intenta presentarse como más real que lo real mismo a través de lo autobiográfico, de lo privado y de su minuciosa documentación. Los tres espectáculos comentados demuestran, en cambio, que la (imposible) presentación de la muerte, del instante preciso del tránsito, sólo puede pensarse, conjeturarse, trasponiéndose en apariencias, remitiendo a sensaciones, transformándose en comentarios, parodiándose bajo la forma de simulacros. Es decir, sólo puede traducirse, interpretarse en imágenes y conceptos.

Son muchos los muertos a los que se alude en los dos monólogos de Los muertos (Ensayo sobre representaciones de muerte en Argentina) de Catani-Pensotti, los cuales, sin embargo, están vivos en tanto son enunciados por actoresintérpretes-traductores. Si muertos están aquellos textos que no se traducen o los que no vuelven a traducirse, ¿están acaso también muertos los textos que no se trasponen, los que no son adaptados a otros lenguajes, los que no son llevados a escena, los que no se confrontan con nuevas miradas? Difícilmente, por cierto, consideraríamos muerto el cuento de Joyce, aun en el caso de que no hubiese sido traducido al lenguaje cinematográfico ni al ámbito escénico a través de modalidades teatrales diferentes articuladas en un mismo espectáculo, tal como sucede en el de Catani-Pensotti. No obstante, es indudable que ambas experiencias traductivas (el cine y el teatro) lo revitalizan en tanto estimulan su lectura o relectura y, por 
consiguiente, sus múltiples reinterpretaciones. "El traducir es la vida del texto; en la traducción, se resiste a morir" (Gómez Ramos, 2000, p. 88). En otras palabras, las muchas formas que adopta la traducción la convierten en una instancia que amplía e ilumina los posibles sentidos del espectáculo al hacer que la analogía explícita entre teatro y cementerio metaforice la analogía entre la finitud humana y la perduración del arte que nos trasciende.

Por otro lado, los dos espectáculos comentados del grupo Krapp también saturan la noción de traducción al intentar interpretar escénicamente las respuestas de los otros a sus propias preguntas sobre la muerte, sobre los límites de la vida y la muerte, sobre la posibilidad e imposibilidad de presentarlas y representarlas en escena. A través de esta exploración, el grupo Krapp se plantea la reflexión sobre la especificidad de su propio discurso artístico, ya que, por sus trabajos anteriores - ¿No me besabas? (1999-2000); Río seco (2001), Mendiolaza (2002-2006); Olympica (2007-2009) - se los conoce fundamentalmente como bailarines o, más imprecisamente, como intérpretes de teatro-danza. Asimismo, reflexionan tanto sobre las posibilidades del teatro y de la danza para traducir escénicamente conceptos, como sobre los alcances y las limitaciones de los diferentes lenguajes verbales y no-verbales que los constituyen. Luciana Acuña intérprete y co-directora, destaca que en (Lado B)

[...] la reflexión sobre la danza nos lleva a un lugar de mucha inocencia, de mucha ingenuidad e incluso ignorancia. Elegimos pensar la danza con el mismo abismo que aparece cuando pensamos en la muerte. La búsqueda del lenguaje fue pensado para bailar como una persona que nunca experimentó en su cuerpo técnica de danza alguna. Toda la obra intenta de algún modo transmitir una sensación de fragilidad, de inocencia, de debilidad y mostrarnos sin recursos ante un hecho extremadamente extraño (Acuña apud Halfon, 2011, online).

Por cierto, tal como señala Cosin (2011), la danza es un lenguaje no transitivo, no es representación en sentido estricto, no es traducible. Sus signos, sus pasos, sus diseños, no admiten mecanismos de codificación y decodificación similar al 
de las palabras y al del sintagma oracional en el marco de una gramática. Sin embargo, en los dos espectáculos de Krapp, hay una fuerte reflexión sobre los límites y los alcances de la danza, sobre la infinita posibilidad de estructurar discursos con lenguajes y con vocabularios originales, altamente sensoriales que apelan directa y francamente a la imaginación y que, partiendo de lo estrictamente personal, de lo autobiográfico, se universalizan.

5. Traducir, que en tercera acepción significa explicar, interpretar, supone diferentes operaciones retóricas, sintácticas, semánticas y pragmáticas entre las lenguas y entre los lenguajes artísticos, entre los géneros y las culturas. Estas múltiples traducciones en imágenes escénicas sobre la muerte, desplegadas en los tres espectáculos, son fundamentalmente formas de explicarla, de intentar interpretarla, a través del ensayismo, entendido como principio constructivo.

El carácter fuertemente ensayístico resulta explícito en el subtítulo del trabajo de Catani-Pensotti e implícito en el del grupo Krapp, ya que la idea de lado $B$ (los ensayos, las pruebas, las experimentaciones, las discusiones grupales para dar forma a una obra futura) remite no sólo como al lugar de la canción secundaria que servía para complementar la principal, el lado A, que realmente se deseaba promocionar en los antiguos vinilos, sino también para designar - en un uso coloquial, actualmente difundido - lo que no se muestra, lo no publicado y, en ocasiones, lo que se suele ocultar, lo ignominioso ${ }^{3}$. En los tres espectáculos se verifican los rasgos que Sánchez (2007) observa en la mayoría de las piezas pensadas desde esta perspectiva ensayística, propia del teatro posdramático: reflexión intelectual, confesión íntima, cita, exposición, juego, humor negro, materiales presentados sin demasiada elaboración, habla, gestualidad y vestuario idénticos a los de la vida cotidiana, exhibición de los trucos y los recursos teatrales propiamente dichos.

El carácter reflexivo de estas traducciones escénicas referidas a la muerte homologa la práctica escénica con el ensayo literario y con el ensayo en tanto momento específico de esa misma práctica escénica. Como el primero, los tres 
espectáculos intentan ser "[...] comprensión del lenguaje del otro e invención de un lenguaje propio; escucha de un sentido comunicado y creación de relaciones inesperadas en el corazón del presente" (Starobinski, 1998, p. 40). Igual que en el ensayo, los tres espectáculos exhiben tanto las preguntas que motivan la escritura (en este caso dramática y escénica) como el proceso de pensamiento que genera las hipotéticas respuestas; persiguen aquello que no podrán alcanzar plenamente y sobreviven en el fragmentarismo consciente de sí; el yo, lo subjetivo de los creadores, plantea una suerte de diálogo íntimo y con el lector (en este caso, espectador) que se siente así no sólo testigo de la tarea creativa, sino que llega a considerarla en parte como propia (Gómez Martínez, 1992).

El ensayo teatral, que no debe confundirse con el llamado training actoral, se tematiza sobre el escenario contemporáneo como matriz reflexiva (Banu, 2005) vinculada a la creación, a lo nuevo, a la invención, al juego, a la definición de roles, tanto para diferenciarse del modelo asiático (ensayar infinitamente para lograr la perfección absoluta del gesto y del movimiento), como para denunciar la ilusión, para diluir las barreras entre lo visto y lo que se oculta, para testimoniar el devenir de la temporalidad en el bios actoral y en la experiencia artística. Al traducir la muerte problematizando, a modo de ensayo literario y teatral, el tiempo, los cuerpos ausentes y presentes, la memoria, las representaciones, las reconstrucciones, lo público y lo privado, lo social y lo individual, los tres espectáculos considerados también hablan - de manera más o menos directa - de teatro, de sus valores, de sus funciones, de su estatuto ficcional, de su capacidad de significar y de comunicar.

Trasponer, adaptar, parafrasear, comentar, parodiar, recodificar, remitir, reescribir, trasladar, transformar, apropiar, citar, mediar, vulgarizar, traicionar, teorizar, interpretar, explicar... ¿todo es traducir? En parte sí, porque la traducción es mucho más que una mera transposición lingüística que hace pasar un texto de una lengua a otra; es, fundamentalmente, una operación intercultural en la que se adaptan sistemas sígnicos diferentes; es una forma de reflexionar sobre lo propio y sobre lo ajeno; un intento de comprendernos y de comprender a los 
otros y es, también, un permanente conflicto entre el deseo de totalidad, de perfección y la aceptación de su imposibilidad.

Intérprete es sinónimo de traductor y de actor. La traducciones, al igual que el teatro, son siempre ejercicios de equivalencia, de semejanza, de invención; son, en última instancia, traiciones, falsificaciones, infidelidades, artificios de la lengua, de la escritura y de la cultura que imponen siempre, ineludiblemente, un regreso a nosotros mismos, una mirada sobre lo propio que nos revela y nos interpreta. Homologar traducción, ensayismo y práctica escénica nos permite entender, desde otra perspectiva, la función y necesidad del teatro en el marco de la cultura contemporánea, signada por la lógica que le imponen los medios masivos y su juego de infinitas mediaciones; nos ayuda a repensar aquello que conocemos a la luz de lo que tales mediaciones nos permiten conocer; nos recuerda básicamente los límites de nuestra condición humana, en la medida en que debemos renunciar al ideal de perfección y elaborar el duelo por la pérdida, por lo intraducible, por lo irrepresentable, en el arte y en la vida. 


\section{Notas}

${ }^{1}$ Se publicó un guión de la obra de Catani-Pensotti: CATANI, Beatriz. Acercamientos a lo Real: textos y escenarios. Buenos Aires: Artes del Sur, 2007. Edição e Coordenação de Óscar Cornago.

${ }^{2}$ Dada la pasión por el cine que Beatriz Catani ha admitido en muchas entrevistas, podríamos suponer que existen en el espectáculo vagas alusiones a la película del joven director argentino Lisandro Alonso, denominada precisamente Los muertos (2004), la cual, como la supuesta obra que Alfredo Martín busca reconstruir, también transcurre en la provincia de Corrientes.

${ }^{3}$ En este último sentido fue empleado en Escoria. El lado B de la fama (2009) de José María Muscari, en la que un grupo de actores desocupados - encarnados por ellos mismos, en una suerte de patética auto ficción - desgranan sus miserias, resentimientos, frustraciones, miedos - mientras beckettianamente esperan a un supuesto productor quien promete volver a llevarlos a la fama que alguna vez tuvieron en el cine y en la televisión. 


\section{Referencias}

BANU, Georges. Perspective à vol d'Oiseau. In: BANU, Georges. Les Répétitions de Stanislavski à Aujourd'hui. Paris: Les temps du theater/Actes Sud, Gallimard, 2005. P. 29-41. CATANI, Beatriz. Acercamientos a lo Real: textos y escenarios. Buenos Aires: Artes del Sur, 2007. Edição e Coordenação de Óscar Cornago.

COSIN, Ale. Sintiéndome Aludida. Alternativa Teatral, Buenos Aires. Disponible en: $<$ http:// www.alternativateatral.com/ver_critica.asp?codigo_critica=285>. Acceso en: 14 abr. 2011.

GÓMEZ MARTÍNEZ, José Luis. Teoría del Ensayo. México: UNAM, 1992.

GÓMEZ RAMOS, Antonio. Entre Líneas: Gadamer y la pertenencia del traductor. Madrid: Visor, 2000.

HALFON, Mercedes. Bailaré hasta Morir (y después también). Suplemento Radar, Buenos Aires, 13 mar. 2011. Disponible en: <http://www.pagina12.com.ar/diario/suplementos/ radar/9-6892-2011-03-13.html>. Acceso en: 14 abr. 2011.

LEHMANN, Hans-Thies. Le Théâtre Postdramatique. Paris: L'Arche, 2002.

LINGENTI, Alejandro. Variaciones sobre la Muerte. Revista Un Caño, Buenos Aires, v. 34, 2011. Disponible en: $<$ http://www.revistauncanio.com.ar/note.php?id=611>. Acceso en: 15 abr. 2011.

MUSITANO, Adriana. Poéticas de lo Cadavérico: teatro, plástica y videoarte de fines del siglo XX. Córdoba: Comunic-Arte, 2011.

SÁNCHEZ, José Antonio. Prácticas de lo Real en la Escena Contemporánea. Madrid: Visor Libros, 2007.

SIBILA, Paula. La Intimidad como Espectáculo. Buenos Aires: Fondo de Cultura Económica, 2008.

STAROBINSKI, Jean. ¿Es posible Definir el ensayo? Cuadernos Hispanoamericanos, Madrid, n. 575, p. 31-20, jul. 1998.

Beatriz Trastoy es doctora en Letras (Universidad de Buenos Aires - UBA), profesora e investigadora de la Facultad de Filosofía y Letras (UBA). Publicó Teatro autobiográfico (2002), Los lenguajes no verbales en el teatro argentino (1997) y Lenguajes escénicos (2006) - estos dos últimos en colaboración con Perla Zayas de Lima -, y numerosos estudios sobre teatro en libros y revistas universitarias de la especialidad. Es directora de telondefondo, Revista de Teoría y Crítica Teatral, primera publicación electrónica sobre temas teatrales de la Universidad de Buenos Aires.

E-mail: btrastoy@hotmail.com 